\title{
ZnMgO quantum dots grown by low-pressure metal organic chemical vapor deposition
}

\author{
Y. J. Zeng, Z. Z. Ye, ${ }^{\text {a) }}$ Y. F. Lu, J. G. Lu, L. Sun, W. Z. Xu, L. P. Zhu, and B. H. Zhao \\ State Key Laboratory of Silicon Materials, Zhejiang University, Hangzhou 310027, \\ People's Republic of China \\ Y. Che \\ IMRA America, Inc., 1044 Woodridge Ave., Ann Arbor, Michigan 48105
}

(Received 16 September 2006; accepted 2 December 2006; published online 3 January 2007)

\begin{abstract}
The authors report on reproducible growth of $\mathrm{ZnMgO}$ quantum dots (QDs) by a metal organic chemical vapor deposition method. $\mathrm{Mg}$ is introduced into $\mathrm{ZnO}$ QDs, as confirmed by x-ray photoelectron spectroscopy and photoluminescence measurements. The size, density, and optical band gap of $\mathrm{ZnMgO}$ QDs can be well controlled by simply modulating the growth parameters.

(C) 2007 American Institute of Physics. [DOI: 10.1063/1.2428853]
\end{abstract}

Due to numerous unique properties expected in the lowdimensional system, nanometer-scale materials promise to be important in the next-generation optoelectronic devices. Among versatile nanostructures, quantum dots (QDs) are of great interest because an ultimate quantum confinement can be established in QDs. ${ }^{1}$ Consequently, considerable research efforts have been devoted to the QD system, including single-electron devices, ${ }^{2,3}$ core/shell structure, ${ }^{4,5}$ QD light emitting, ${ }^{6,7}$ and biological applications. ${ }^{8,9}$

$\mathrm{ZnO}$ is presently receiving worldwide attention because of its advantages for blue/UV light emitters and detectors. ${ }^{10,11}$ Research activity on $\mathrm{ZnO}$ QDs has extensively increased over the past few years. ${ }^{12-16}$ In addition, dopingthe intentional introduction of impurities-is fundamental to controlling the properties of semiconductors. It is known that the band gap of bulk $\mathrm{ZnO}$ can be tuned by alloying with $\mathrm{MgO}$ or CdO. Especially, the recent breakthrough in $p$-type doping bottleneck has made the potentials of $\mathrm{ZnO}$ materials more feasible. ${ }^{17-20}$ In these regards, similar efforts to dope $\mathrm{ZnO}$ QDs are strongly demanded. However, there have been few reports on this issue so far. In this letter, we develop a metal organic chemical vapor deposition (MOCVD) method to prepare $\mathrm{ZnMgO}$ QDs. The tailored properties of the QDs are readily presented.

QD samples were grown by a low-pressure MOCVD method. The substrates were $n$-type silicon wafers with $3^{\circ}$ bias oriented from $\langle 111\rangle$. Diethylzinc and $\mathrm{O}_{2}$ were used as the zinc source and the oxygen source, respectively. $\mathrm{N}_{2}$ was used as the carrier gas. Bis(cyclopentadienyl)magnesium $\left(\mathrm{Cp}_{2} \mathrm{Mg}\right)$ and bis(methylcyclopentadienyl)magnesium $\left[(\mathrm{MeCp})_{2} \mathrm{Mg}\right]$ were used as the magnesium source. The growth temperature ranged from 350 to $450{ }^{\circ} \mathrm{C}$. The chamber pressure was maintained at $6 \mathrm{~Pa}$ during the growth process. The crystal structures and morphologies of the $\mathrm{ZnMgO}$ QDs were characterized by $x$-ray diffraction (XRD) $(\mathrm{Cu} K \alpha \lambda=1.541 \AA)$ and field-emission scanning electron microscopy (FE-SEM) (FEI Sirion 200 FEG). The chemical states of $\mathrm{Mg}$ were analyzed by x-ray photoelectron spectroscopy (XPS) (Thermo ESCALAB 250, Al $K \alpha$ radiation source $h \nu=1486.6 \mathrm{eV})$. Room-temperature photolumines-

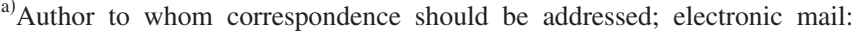
yezz@zju.edu.cn cence (PL) measurements were performed using a $\mathrm{He}-\mathrm{Cd}$ $325 \mathrm{~nm}$ laser as the excitation source. The electrical properties were examined by scanning tunneling microscopy (STM) (SPM Solver P47) at room temperature.

Figure 1 shows XRD pattern of the $\mathrm{ZnMgO}$ QDs grown at $400{ }^{\circ} \mathrm{C}$. Only two peaks corresponding to $\mathrm{ZnO}(002)$ and $\mathrm{Si}$ (111) planes are observed, suggesting a total (002) preferential orientation for the $\mathrm{ZnMgO}$ QDs. The $34.4^{\circ}$ (002) diffraction angle is in well agreement with $\mathrm{ZnO}$ bulk single crystal, implying that no evident residual stress or inclusioninduced lattice distortion due to $\mathrm{Mg}$ doping has developed during the growth process. According to the Debye-Scherrer method, the mean grain size of the QDs is calculated to be $10.2 \mathrm{~nm}$.

Figure 2 illustrates FE-SEM top view images of the $\mathrm{Zn}$ $\mathrm{MgO}$ QDs grown at different temperatures. The QDs show an average diameter around $9 \mathrm{~nm}$, which is consistent with the XRD results. As evident in the images, the density of the QDs is strongly temperature dependent. It decreases as the growth temperature increases, which can be explained in terms of the degree of supercooling. When the substrate temperature is low (e.g., $350^{\circ} \mathrm{C}$ ), the degree of supercooling is large. This results in a high density of nucleation center, and thus a high density of QDs is obtained, as shown in Fig. 2(a). Also, the opposite holds true for the high-temperature growth [e.g., $450{ }^{\circ} \mathrm{C}$, Fig. 2(c)].

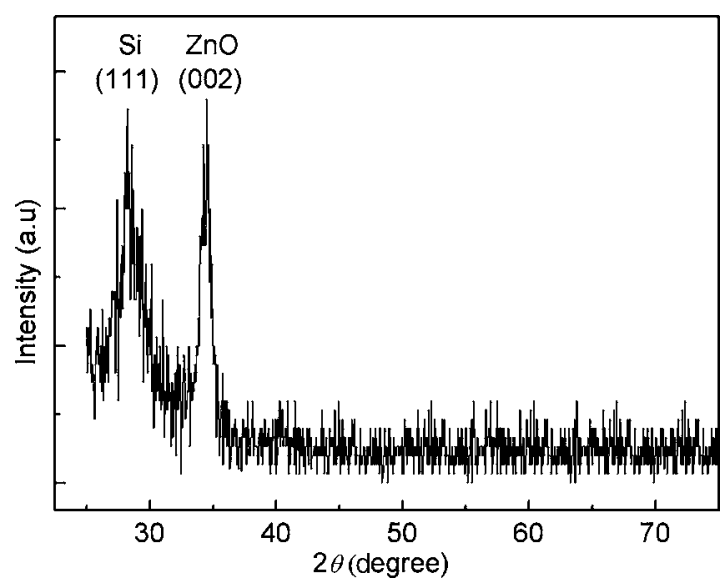

FIG. 1. XRD pattern of $\mathrm{ZnMgO}$ QDs grown at $400{ }^{\circ} \mathrm{C}$. 


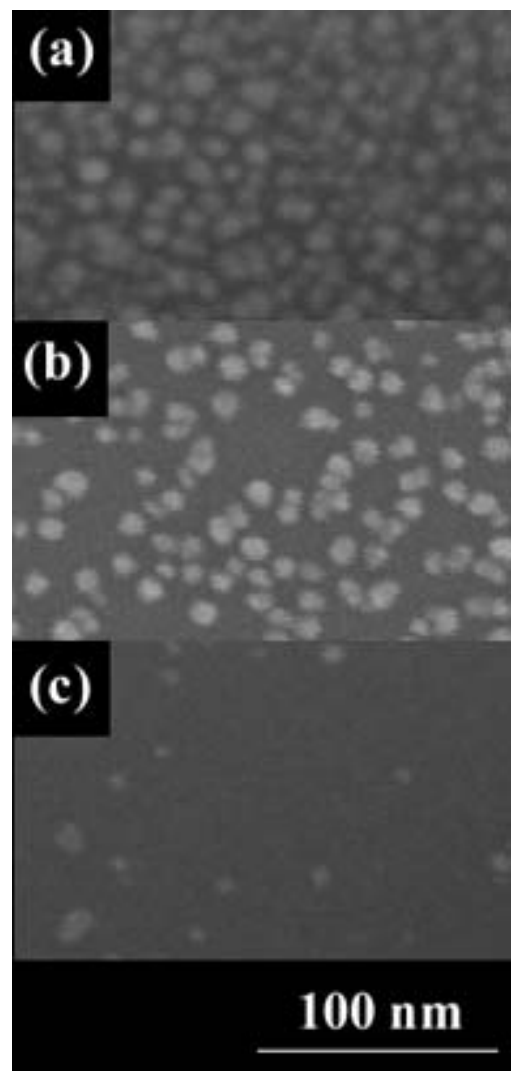

FIG. 2. FE-SEM top view images of $\mathrm{ZnMgO}$ QDs grown at different temperatures: (a) $350{ }^{\circ} \mathrm{C}$, (b) $400{ }^{\circ} \mathrm{C}$, and (c) $450{ }^{\circ} \mathrm{C}$.

Another striking feature of the SEM images is that the average diameter of the QDs decreases with the increased temperature, especially in the case of high-temperature growth of $450{ }^{\circ} \mathrm{C}$. This is because a self-assemble process can be influenced by the balance between adsorption and desorption of the reactive atoms. When the growth temperature is low, the process of adsorption is much more exquisite. Therefore, a high growth rate and a large diameter of the QDs are expected, as seen in Fig. 2(a). As the growth temperature increases, the balance between adsorption and desorption varies, which results in a low growth rate and corresponding small average diameter of the QDs [Fig. 2(c)]. It should be emphasized that the above-introduced dependence of the size and density of QDs on the growth temperature is not accidental and has been consistently repeated. These controllable characteristics are, therefore, well expected to offer better performance for the future devices based on $\mathrm{ZnMgO}$ QDs.

Much work has been reported on $\mathrm{ZnMgO}$ thin films. ${ }^{21}$ Also, quantum confinement has been observed in $\mathrm{ZnO} / \mathrm{ZnMgO}$ nanorod heterostructures. ${ }^{22}$ Considering that a doping principle, applicable to bulk materials, may be quite different from a QD system, ${ }^{23} \mathrm{Mg}$ doping behavior, however, remains unclear in $\mathrm{ZnO}$ QD system. As a consequence, the chemical bonding states of $\mathrm{Mg}$ in $\mathrm{ZnO}$ QDs were examined by XPS. Figure 3 shows the $\mathrm{Mg} 1 s$ narrow scan spectrum for the QDs grown at $400{ }^{\circ} \mathrm{C}$. A peak around $1303.6 \mathrm{eV}$ is observed, which is attributed to the $\mathrm{Mg} 1 s$ core level. Thus, it is well confirmed that $\mathrm{Mg}$ is introduced into $\mathrm{ZnO}$ QDs.

In addition to XPS, PL measurements were performed to provide further evidence for the introduction of $\mathrm{Mg}$. Figure 4 compares the PL spectra for the $\mathrm{ZnO}$ thin film, $\mathrm{ZnO}$ QDs, Downloaded 04 Jan 2007 to 218.108.29.238. Redistribution subject

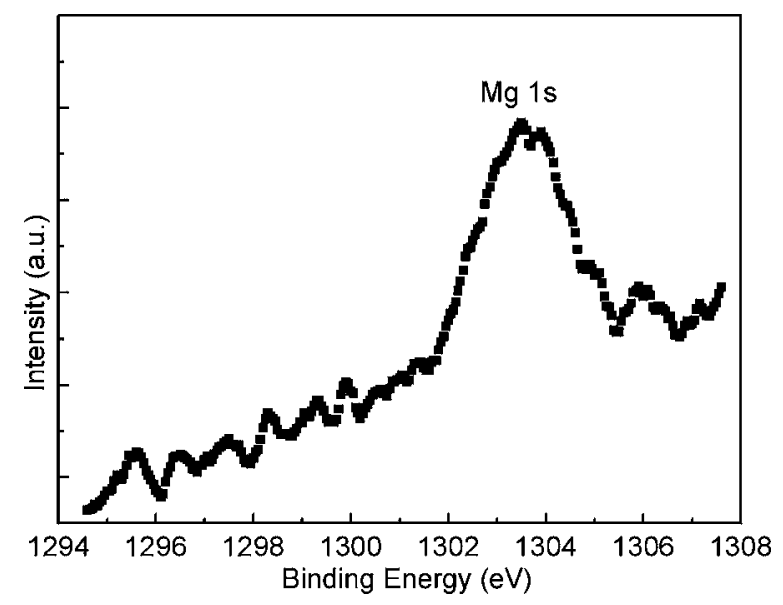

FIG. 3. XPS narrow scan spectrum of $\mathrm{Mg} 1 s$ region for $\mathrm{ZnMgO}$ QDs grown at $400{ }^{\circ} \mathrm{C}$.

and $\mathrm{ZnMgO}$ QDs. ZnO thin film shows a dominant nearband-edge peak at $375.5 \mathrm{~nm}$, which is attributed to a free exciton (FX) emission, whereas the FX emission of the $\mathrm{ZnO}$ QDs shows a blueshift to $372.6 \mathrm{~nm}$, which is believed to be the result of quantum confinement effects. As expected, the $\mathrm{FX}$ emission of the $\mathrm{ZnMgO}$ QDs grown with $\mathrm{Cp}_{2} \mathrm{Mg}$ source undergoes a further blueshift to $370.1 \mathrm{~nm}$. Note that SEM and atomic force microscopy measurements reveal the same average diameter around $9 \mathrm{~nm}$ and height around $6 \mathrm{~nm}$ for the $\mathrm{ZnMgO}$ and $\mathrm{ZnO}$ QDs (data not shown). It is, therefore, inferred that both quantum confinement effects and $\mathrm{Mg}$ doping contribute to the band gap widening simultaneously in our $\mathrm{ZnMgO}$ QDs. Furthermore, the FX emission shifts to $366.8 \mathrm{~nm}$ for the $\mathrm{ZnMgO}$ QDs grown with $(\mathrm{MeCp})_{2} \mathrm{Mg}$ source. This further blueshift is associated with the increased $\mathrm{Mg}$ content because the $(\mathrm{MeCp})_{2} \mathrm{Mg}$ source possesses a higher vapor pressure in comparison with $\mathrm{Cp}_{2} \mathrm{Mg}$. This inference is also supported by the fact that the $\mathrm{Mg}$ content in these two $\mathrm{ZnMgO}$ QDs are $1.1 \%$ and $2.3 \%$, respectively, obtained from XPS measurements. The comparative PL spectra suggest that the $\mathrm{Mg}$ content can be tuned and a tailored optical band gap is achieved for the $\mathrm{ZnMgO}$ QDs.

Finally, the effects of $\mathrm{Mg}$ incorporation on electrical properties of $\mathrm{ZnMgO}$ QDs were characterized by STM. The tip of the probe contacted directly with the QD, eliminating any tunnel current. Figure 5 illustrates the current-voltage

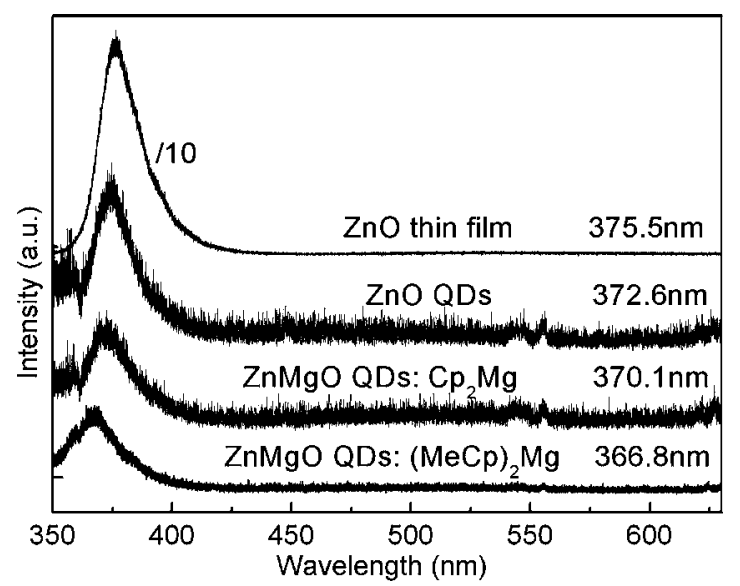

FIG. 4. Comparative room-temperature PL spectra for $\mathrm{ZnO}$ thin film, $\mathrm{ZnO}$ QDs, and $\mathrm{ZnMgO}$ QDs grown at $400{ }^{\circ} \mathrm{C}$.

to AIP license or copyright, see http://apl.aip.org/apl/copyright.jsp 


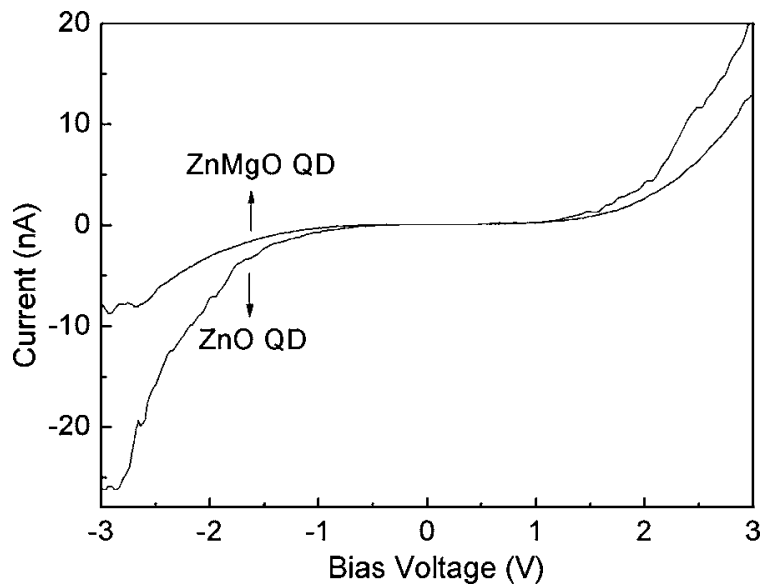

FIG. 5. STM $I$ - $V$ characteristics of $\mathrm{ZnO}$ and $\mathrm{ZnMgO}$ QDs grown at $400^{\circ} \mathrm{C}$.

$(I-V)$ characteristics of the $\mathrm{ZnO}$ and $\mathrm{ZnMgO}$ QDs grown at $400{ }^{\circ} \mathrm{C}$. The nonlinear $I-V$ characteristic for the both samples indicates a barrier between the tip and QDs, which is probably associated with the native defects in QDs. ${ }^{24}$ The current of the $\mathrm{ZnMgO}$, however, is always smaller than that of $\mathrm{ZnO}$. It is possible that the $\mathrm{Mg}$ incorporation increases the barrier height for the $\mathrm{ZnMgO}$ QDs. Also, there is a possibility that the addition of $\mathrm{Mg}$ moves the conduction band edge up in energy and potentially away from the intrinsic shallow donor state. ${ }^{25}$ Correspondingly, an increase in activation energy of the defect donors and resistivity of the QDs is expected for the $\mathrm{ZnMgO}$ QDs.

In summary, we have demonstrated reproducible growth of $\mathrm{ZnMgO}$ QDs by a MOCVD method. The size, density, and optical band gap of the QDs can be well controlled by simply modulating the growth parameters. In addition, an evident change in QD transport properties due to introduction of $\mathrm{Mg}$ is observed. Considering all the tunable characteristics and the standard MOCVD technology, incorporating $\mathrm{ZnMgO}$ QDs into future optoelectronic devices deserves an eager expectation.

This work was supported by National Natural Science Foundation of China under Contract Nos. 50532060, 50572095, and 60340460439.
${ }^{1}$ J. Stangl, V. Holy, and G. Bauer, Rev. Mod. Phys. 76, 725 (2004).

${ }^{2}$ T. H. Oosterkamp, T. Fujisawa, W. G. van der Wiel, K. Ishibashi, R. V. Hijman, S. Tarucha, and L. P. Kouwenhoven, Nature (London) 395, 873 (1998).

${ }^{3}$ Uri Banin, YunWei Cao, David Katz, and Oded Millo, Nature (London) 400, 542 (1999).

${ }^{4}$ Jörg J. Schneider, Adv. Mater. (Weinheim, Ger.) 13, 529 (2001).

${ }^{5}$ Daocheng Pan, Qiang Wang, Shichun Jiang, Xiangling Ji, and Lijia An, Adv. Mater. (Weinheim, Ger.) 17, 176 (2005).

${ }^{6}$ Jialong Zhao, Julie A. Bardecker, Andrea M. Munro, Michelle S. Liu, Yuhua Niu, I-Kang Ding, Jingdong Luo, Baoquan Chen, Alex K.-Y. Jen, and David S. Ginger, Nano Lett. 6, 463 (2006).

${ }^{7}$ Yang-Wei Lin, Wei-Lung Tseng, and Huan-Tsung Chang, Adv. Mater. (Weinheim, Ger.) 18, 1381 (2006).

${ }^{8}$ X. Michalet, F. F. Pinaud, L. A. Bentolila, J. M. Tsay, S. Doose, J. J. Li, G. Sundaresan, A. M. Wu, S. S. Gambhir, and S. Weiss, Science 307, 538 (2005).

${ }^{9}$ John P. Zimmer, Sang-Wook Kim, Shunsuke Ohnishi, Eichii Tanaka, John V. Frangioni, and Moungi G. Bawendi, J. Am. Chem. Soc. 128, 2526 (2006).

${ }^{10}$ D. C. Look, Mater. Sci. Eng., B 80, 383 (2001).

${ }^{11}$ S. J. Pearton, D. P. Norton, K. Ip, Y. W. Heo, and T. Steiner, Prog. Mater. Sci. 50, 293 (2005).

${ }^{12}$ Sang-Woo Kim, Shizuo Fujita, and Shigeo Fujita, Appl. Phys. Lett. 81, 5036 (2002).

${ }^{13}$ Vladimir A. Fonoberov and Alexander A. Balandin, Appl. Phys. Lett. 85, 5971 (2004).

${ }^{14}$ J. G. Lu, Z. Z. Ye, J. Y. Huang, L. P. Zhu, B. H. Zhao, Z. L. Wang, and Sz. Fujita, Appl. Phys. Lett. 88, 063110 (2006).

${ }^{15} \mathrm{Hsin}-\mathrm{Ming}$ Cheng, Kuo-Feng Lin, Hsu-Cheng Hsu, and Wen-Feng Hsieh, Appl. Phys. Lett. 88, 261909 (2006).

${ }^{16}$ H. Amekura, O. A. Plaksin, M. Yoshitake, Y. Takeda, and N. Kishimoto, and Ch. Buchal, Appl. Phys. Lett. 89, 023115 (2006).

${ }^{17}$ A. Tsukazaki, A. Ohtomo, T. Onuma, M. Ohtani, T. Makino, M. Sumiya, K. Ohtani, S. Chichibu, S. Fuke, Y. Segawa, H. Ohno, H. Koinuma, and M. Kawasaki, Nat. Mater. 4, 42 (2005).

${ }^{18}$ W. Z. Xu, Z. Z. Ye, Y. J. Zeng, L. P. Zhu, B. H. Zhao, L. Jiang, J. G. Lu, H. P. He, and S. B. Zhang, Appl. Phys. Lett. 88, 173506 (2006).

${ }^{19}$ Y. Ryu, T.-S. Lee, Jorge A. Lubguban, Henry W. White, B.-J. Kim, Y.-S. Park, and C.-J. Youn, Appl. Phys. Lett. 88, 241108 (2006).

${ }^{20}$ Y. J. Zeng, Z. Z. Ye, W. Z. Xu, D. Y. Li, J. G. Lu, L. P. Zhu, and B. H. Zhao, Appl. Phys. Lett. 88, 062107 (2006).

${ }^{21}$ Ü. Özgür, Ya. I. Alivov, C. Liu, A. Teke, M. A. Reshchikov, S. Doğan, V. Avrutin, S.-J. Cho, and H. Morkocd, J. Appl. Phys. 98, 041301 (2005).

${ }^{22}$ Won Il Park, Gyu-chul Yi, Miyoung Kim, and Stephen J. Pennycook, Adv. Mater. (Weinheim, Ger.) 15, 526 (2003).

${ }^{23}$ Steven C. Erwin, Lijun Zu, Michael I. Haftel, Alexander L. Efros, Thomas A. Kennedy, and David J. Norris, Nature (London) 436, 91 (2005).

${ }^{24}$ Yukio Sato, James P. Buban, Teruyasu Mizoguchi, Naoya Shibata, Masatada Yodogawa, Takahisa Yamamoto, and Yuichi Ikuhara, Phys. Rev. Lett. 97, 106802 (2006).

${ }^{25}$ Y. W. Heo, Y. W. Kwon, Y. Li, S. J. Pearton, and D. P. Norton, Appl. Phys. Lett. 84, 3474 (2004). 